\title{
Verificação do dano muscular através da avaliação da concentração de creatina quinase em indivíduos não atletas após prova de ciclismo não competitivo
}

\author{
Evaluation of muscle damage by assessment of the concentration of creatine kinase \\ in non-athlete individuals after uncompetitive cycling race
}

\author{
Mateus Schneider ${ }^{1}$, Eduardo Périco² ${ }^{2}$, Adriane Pozzobon ${ }^{3} \bowtie$ \\ ${ }^{1}$ Especialista em Fisiologia do Exercício e do Desporto, Centro Universitário UNIVATES. \\ 2 Doutor em Ecologia pela Universidade de São Paulo (USP). Professor Titular da Univates, Centro de Ciências Biológicas e Saúde. \\ ${ }^{3}$ Doutor em Ciências Biológicas/Fisiologia pela Universidade Federal do Rio Grande do Sul (UFRGS). Professora Titular da Univates, \\ Centro de Ciências Biológicas e Saúde.
}

\section{RESUMO}

Objetivos: Investigar os níveis séricos da enzima creatina quinase em ciclistas não profissionais após uma prova de ciclismo não competitivo de $300 \mathrm{~km}$, para avaliação de dano muscular.

Métodos: Participaram do estudo 12 ciclistas do sexo masculino, com as seguintes médias para os parâmetros antropométricos: idade $38,1 \pm 11,5$ anos, estatura $1,77 \pm 7,7 \mathrm{~cm}$, peso $77 \pm 8,5 \mathrm{~kg}$, percentual de gordura $12,0 \pm 4,1 \%$ e índice de massa corporal $24,7 \pm 2,6 \mathrm{~kg} / \mathrm{m}^{2} .0 \mathrm{~s}$ níveis séricos de creatina quinase foram avaliados antes e imediatamente após a prova, através de método cinético.

Resultados: O estudo demonstrou que após a prova de $300 \mathrm{~km}$ houve uma elevação média de $480 \%$ nos níveis séricos de creatina quinase $(\mathrm{p}<0,0001)$. Nenhuma correlação foi encontrada entre os níveis de creatina quinase e o índice de massa corporal ou o tempo de prova.

Conclusões: Estes dados demonstram elevação nos níveis séricos de creatina quinase após uma prova de ciclismo não competitivo de $300 \mathrm{~km}$, sugerindo a presença de dano muscular nessa modalidade de ciclismo.

DESCRITORES: creatina quinase; exercício; músculo; ciclismo.

\section{ABSTRACT}

Aims: To investigate the serum levels of the enzyme creatine kinase in non-professional cyclists after a non-competitive cycling race of $300 \mathrm{~km}$, for evaluation of muscle damage.

Methods: The study included 12 male cyclists, with the following means for the anthropometric parameters: age $38.1 \pm 11.5$ years, height $1.77 \pm 7.7 \mathrm{~cm}$, weight $77 \pm 8.5 \mathrm{~kg}$, fat percentage $12.0 \pm 4.1 \%$, and body mass index $24.7 \pm 2.6 \mathrm{~kg} / \mathrm{m}^{2}$. Serum levels of creatine kinase were assessed before and immediately after the race, through kinetic method.

Results: The study showed that after the $300 \mathrm{~km}$ race there was an average increase of $480 \%$ in serum levels of creatine kinase ( $<<0.0001$ ). No correlation was found between creatine kinase levels and body mass index or time of race.

Conclusions: These data show increase in serum levels of creatine kinase after a non-competitive cycling race of $300 \mathrm{~km}$, suggesting the presence of muscle damage in this cycling mode.

KEY WORDS: creatine kinase; exercise; muscle; cycling. 


\section{INTRODUÇÃO}

O exercício físico aeróbio tem sido considerado por muitos como um importante aliado na busca de melhorias, no que se refere à aptidão física, qualidade de vida e composição corporal. Ele promove alterações metabólicas e cardiorrespiratórias, além de promover significante elevação do gasto calórico, contribuindo para a redução dos fatores de risco de doenças relacionadas ao estilo de vida sedentário. Entretanto, quando o exercício é conduzido de forma prolongada e extenuante, pode provocar dano muscular [1].

A enzima creatina quinase $(\mathrm{CK})$ apresenta três isoformas citoplasmáticas: CK-BB, CK-MB e CK-MM. A CK-MM é usualmente encontrada em doenças ou lesão muscular, enquanto que a CK-MB ocorre no miocárdio e a CK-BB no cérebro ou trato gastrintestinal [2]. A CK é considerada um potente marcador de dano muscular, pois não possui a capacidade de atravessar a membrana plasmática da célula muscular em condições normais e, portanto, elevações séricas da enzima sugerem o extravasamento da mesma para o líquido extracelular por dano celular. $\mathrm{O}$ músculo esquelético contém quase inteiramente CK-MM, e uma pequena quantidade de CK-MB [3]. $\mathrm{O}$ soro normal contém cerca de $90-100 \%$ de CK-MM, sendo que, indivíduos hígidos ao apresentarem aumento na concentração de $\mathrm{CK}$, podem apresentar lesão no músculo esquelético [4].

Variáveis fisiológicas e fatores externos, tais como gênero, idade, raça, massa muscular, condições climáticas e exercício físico, assim como injeções intramusculares, influenciam nos níveis de CK [5]. Os fatores bioquímicos e a sobrecarga mecânica decorrentes de exercícios intensos e prolongados promovem lesões ao tecido muscular. Essas injúrias promovem danos a diversas estruturas da fibra muscular, tais como membranas, túbulos transversos e miofibrilas. Assim, enzimas musculares ou proteínas são marcadores de dano no tecido muscular. São descritos aumentos de até quatro vezes nos níveis de mioglobina e CK após o exercício [1].

De um modo geral, a elevação dos níveis de CK ocorre em maiores proporções após exercícios prolongados, de ultrarresistência de predominância aeróbia. Da mesma forma, exercícios de contrações musculares excêntricas com levantamento de peso e corridas em declive também provocam significativas alterações. O pico de elevação sérica de CK ocorre geralmente até 72 horas após o exercício, retornando posteriormente de maneira gradual a níveis basais [6]. Em pessoas que fazem treinamento os níveis de CK podem permanecer elevados, entretanto, durante o exercício o aumento é menor quando comparado ao que ocorre nos indivíduos sedentários [7].

Diversas modalidades esportivas vêm apresentando um aumento da popularidade. Dentre elas pode se citar maratona, corrida de aventura e triathlon de longa distância (como Ironman), todas caracterizadas por serem de longa duração e de predominância aeróbia. Entretanto, são provas muito extenuantes, motivo pelo qual a demanda de oxigênio pelos músculos aumenta consideravelmente, refletindo no estresse oxidativo com maior geração de radicais livres e dano aos lipídeos e proteínas de membrana [8].

Hartmann et al. [9] detectaram aumento nos níveis de CK em atletas após treino de força de moderado a intenso, ou treino aeróbio. Dessa forma, o dano muscular após atividades aeróbias de longa duração, como ciclismo e corridas, pode ser avaliado por marcadores enzimáticos. Embora a relação entre as concentrações de CK e o exercício seja bem descrita na literatura, muitos estudos apresentam dados divergentes conforme a modalidade esportiva, além de existirem poucos estudos recentes com ciclistas. Portanto, estudos que avaliem as variações de CK em diferentes modalidades esportivas contribuem para a compreensão dos mecanismos relacionados ao dano muscular. Uma amostra de indivíduos não atletas pode ser mais indicada para avaliação aguda do dano muscular após a atividade, já que, como citado anteriormente, o treinamento pode manter a elevação dos níveis de CK. Frente ao exposto, o presente trabalho teve como objetivo analisar os níveis séricos de CK em ciclistas não profissionais após uma prova de ciclismo não competitivo, para avaliar o dano muscular nessa modalidade esportiva.

\section{MÉTODOS}

O presente estudo, de caráter transversal, foi realizado durante uma prova masculina de ciclismo não competitivo no interior do Rio Grande do Sul. Os sujeitos foram previamente convidados a participar da pesquisa. Foram incluídos homens com idade entre 30 e 50 anos, caucasianos, sem histórico de doença cardiovascular e não atletas, que assinaram o Termo de Consentimento Livre e Esclarecido. Foram excluídos indivíduos que relataram ter recebido qualquer tipo de injeção intramuscular, que tinham histórico de doença cardíaca, ou que relataram ter feito exercício físico prolongado durante as 72 horas anteriores ao teste. $\mathrm{O}$ 
estudo foi aprovado pelo Comitê de Ética do Centro Universitário UNIVATES (Resolução 060/2010 de 23/06/2010).

Os 12 participantes selecionados foram submetidos à avaliação antropométrica, sendo aferidos peso, altura e dobras cutâneas, assim como a análises sanguíneas. Para a análise dos níveis séricos de CK, os participantes foram previamente informados sobre a importância do relato das atividades físicas na semana que antecedeu a prova, as quais poderiam influenciar nos resultados. $\mathrm{O}$ consumo de água, alimentos, suplementos e repositores hidroeletrolíticos foi realizado ad libitum pelos ciclistas, antes e durante a prova. A prova de ciclismo não competitivo em estudo é considerada do tipo Audax (Randonnéur), ou seja, uma prova com percurso definido, de longa distância e com ritmo controlado [10]. Essa modalidade permite a participação de ciclistas não profissionais, os quais foram os sujeitos da pesquisa.

Imediatamente antes e após a realização do percurso, foram coletados dos participantes $5 \mathrm{ml} \mathrm{de}$ sangue total, sendo que na coleta pré-prova os ciclistas não estavam em jejum. A determinação quantitativa da atividade da CK total foi feita utilizando-se metodologia cinética no equipamento Cobas Mira ${ }^{\circledR}$, da marca Roche ${ }^{\circledR}$ (Rotkreuz, Suíça). O kit utilizado foi o CK-NAC Liquiform ${ }^{\circledR}$, da marca Labtest ${ }^{\circledR}$ (Lagoa Santa, Minas Gerais). Os valores de referência adotados para homens adultos foram de 26 a $189 \mathrm{U} / \mathrm{L}$.

Para a aferição de peso corporal, estatura e dobras cutâneas utilizaram retrospectivamente uma balança digital modelo BK30 (Black \& Decker ${ }^{\circledR}$, Baltimore, Maryland, EUA), um estadiômetro Physicus ${ }^{\circledR}$ (Auriflama, São Paulo) e um plicômetro Pró Fisiomed ${ }^{\circledR}$ (Porto Alegre, Rio Grande do Sul). O peso e a altura foram usados para cálculo de índice de massa corporal (IMC). Para critério de diagnóstico foram utilizados os parâmetros recomendados pela Organização Mundial de Saúde [11]. As dobras cutâneas avaliadas foram peitoral, abdominal e coxa. Os valores das dobras foram inseridos na equação para estimativa de percentual de gordura de Jackson e Pollock [12].

Os dados foram expressos em valores absolutos. Como os dados de CK antes e depois da prova não apresentavam normalidade, foram transformados utilizando $\ln (\mathrm{X}+1)$ e, depois testados pelo teste de D'Agostino, que indicou normalidade. Para comparação entre os valores das concentrações da CK antes e após a prova utilizou-se o teste $t$ de Student para amostras pareadas. A relação entre o IMC e os níveis de CK foi feita através da Correlação de Pearson. Considerou-se o $\mathrm{P} \leq 0,05$. A análise estatística foi feita no software Bioestat 5.0.

\section{RESULTADOS}

Foram avaliados 12 ciclistas que totalizaram o percurso de $300 \mathrm{~km}$ da prova de Audax. O tempo de prova, a idade média dos participantes e os dados antropométricos estão apresentados individualmente na Tabela 1. A média do IMC foi de $24,7 \pm 2,6 \mathrm{~kg} / \mathrm{m}^{2}$, indicando eutrofia.

Tabela 1. Idade, dados antropométricos e tempo de realização da prova para cada um dos 12 ciclistas e média dos dados.

\begin{tabular}{|c|c|c|c|c|c|c|}
\hline Ciclista & Idade (anos) & Peso (kg) & Estatura $(\mathrm{cm})$ & IMC (kg/m2) & $\% \mathrm{G}$ & Tempo (min) \\
\hline A & 51 & 75,7 & 172 & 25,58 & 9,46 & 993 \\
\hline B & 52 & 63,5 & 170 & 21,97 & 14,27 & 956 \\
\hline $\mathrm{C}$ & 21 & 81,1 & 182 & 24,48 & 11,12 & 897 \\
\hline $\mathrm{D}$ & 20 & 63,3 & 176 & 20,43 & 7,34 & 897 \\
\hline E & 34 & 85,7 & 183 & 25,59 & 17,83 & 1148 \\
\hline $\mathrm{F}$ & 31 & 77,4 & 180 & 23,88 & 9,2 & 990 \\
\hline G & 48 & 76 & 169 & 26,6 & 12,9 & 1145 \\
\hline $\mathrm{H}$ & 49 & 69 & 169 & 24,15 & 9,24 & 932 \\
\hline I & 34 & 82 & 194 & 21,78 & 11,72 & 956 \\
\hline J & 38 & 88 & 175 & 28,73 & 15,39 & 1172 \\
\hline L & 49 & 86,5 & 172 & 29,23 & 19,54 & 1180 \\
\hline M & 30 & 82,7 & 185 & 24,16 & 6,53 & 993 \\
\hline Média $\pm D P$ & $38,1 \pm 11,5$ & $77,7 \pm 8,5$ & $177,3 \pm 7,7$ & $24,7 \pm 2,6$ & $12,0 \pm 4,1$ & $1021 \pm 108$ \\
\hline
\end{tabular}

IMC: índice de massa corporal; \%G: porcentagem de gordura corporal; DP: desvio padrão. 
Os dados dos níveis séricos da CK para cada ciclista estão apresentados na Tabela 2. Os dados do percentual de aumento mostram uma elevação da CK após a prova, no entanto nenhuma correlação foi encontrada entre o tempo de prova (em minutos) e a elevação da CK.

Os dados coletados mostram um incremento significativo $(\mathrm{p}=0,0087)$ dos níveis séricos de CK após a prova, quando comparados com os níveis da CK antes da prova. A Figura 1 apresenta os valores de CK para cada indivíduo, antes e após a prova, e a relação com o IMC. Estatisticamente não foi encontrada relação entre os valores de CK observados nos dois momentos e o IMC.

\section{DISCUSSÃO}

Os dados obtidos no presente estudo mostram que o grupo avaliado apresentou um aumento significativo nos níveis séricos de CK imediatamente após a prova de ciclismo de $300 \mathrm{~km}$, sugerindo possível dano muscular. As dosagens de CK e outras enzimas geralmente estão associadas ao dano muscular, pois essas moléculas estão localizadas no citosol da célula, não sendo capazes de atravessar a membrana celular. Dessa forma, sua dosagem pode ser adotada como método indireto para análise de dano muscular.

Tabela 2. Níveis de creatina quinase em 12 ciclistas antes e após prova de $300 \mathrm{~km}$ e percentual de aumento.

\begin{tabular}{|c|c|c|c|}
\hline Ciclista & $\begin{array}{c}\text { Creatina quinase }(\mathbf{U} / \mathbf{L}) \\
\text { Pré-prova }\end{array}$ & $\begin{array}{c}\text { Creatina quinase }(\mathbf{U} / \mathbf{L}) \\
\text { Pós-prova }\end{array}$ & \% de aumento \\
\hline A & 206 & 1113 & 440,3 \\
\hline B & 80 & 391 & 388,8 \\
\hline C & 117 & 311 & 165,8 \\
\hline D & 157 & 291 & 85,4 \\
\hline E & 79 & 560 & 608,9 \\
\hline F & 121 & 1342 & 1009,1 \\
\hline G & 272 & 3442 & 1165,4 \\
\hline H & 130 & 990 & 661,5 \\
\hline I & 135 & 603 & 346,7 \\
\hline J & 141 & 974 & 590,8 \\
\hline L & 207 & 308 & 48,8 \\
\hline M & 206 & 730 & 254,4 \\
\hline Média \pm DP & $154,3 \pm 57,8$ & $921,3 \pm 867,1$ & $480,5 \pm 347,8$ \\
\hline
\end{tabular}

DP: Desvio padrão. Teste t para amostras pareadas: $p=0,0087$

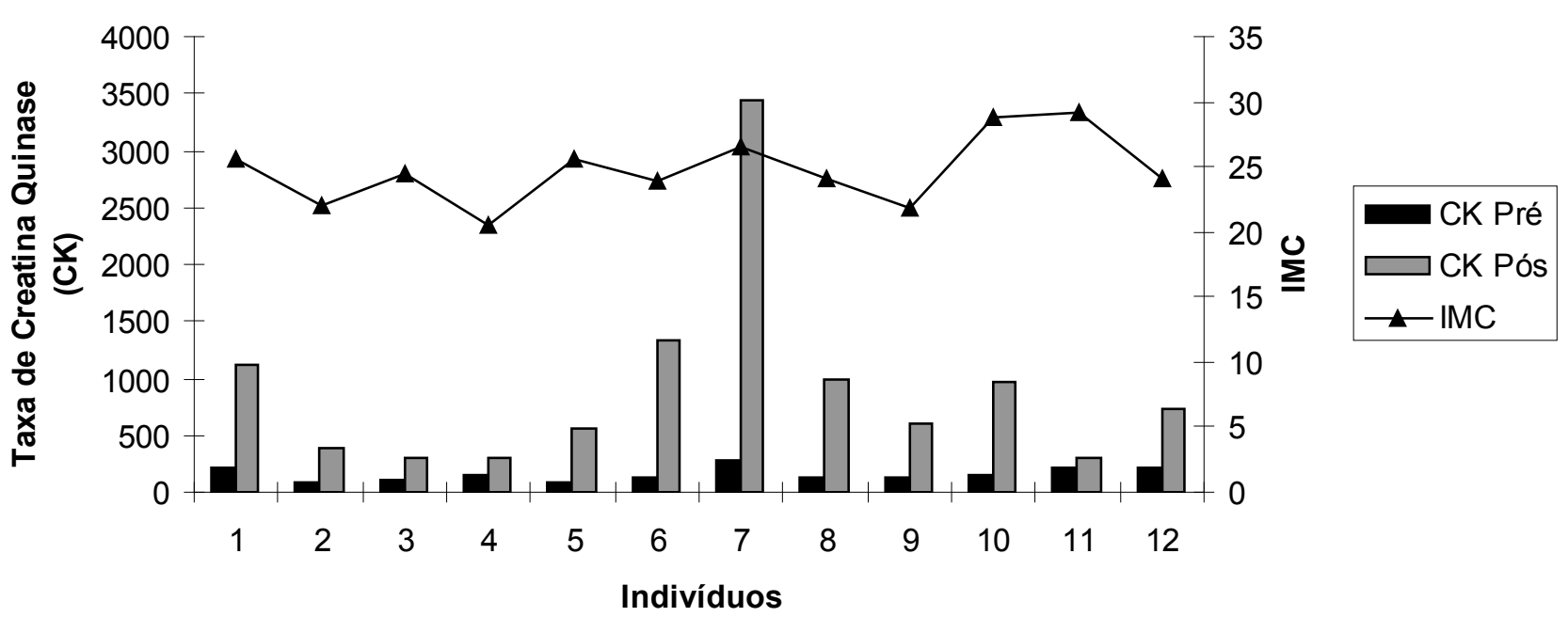

Figura 1. Valores de creatina quinase (U/L) por indivíduo, antes e após a prova de ciclismo de 300 km, e o índice de massa corporal (IMC), em 12 ciclistas não profissionais. 
Existem poucos estudos que avaliem parâmetros bioquímicos de dano muscular em ciclistas. A maioria dos estudos evidencia a elevação dos níveis de CK ao dano muscular em outras modalidades esportivas. Um estudo com 38 homens saudáveis e sedentários os quais participaram de um programa de treinamento para maratona avaliou o efeito do treinamento durante 30 semanas. Os níveis de $\mathrm{CK}$ dos avaliados apresentou uma elevação significativa entre o início e a 15ํㅗㄹ semana de treinamento, entretanto, o mesmo não ocorreu entre a $15^{\mathrm{a}}$ e $30^{\mathrm{a}}$ semana, fato que demonstra uma relação direta entre a melhora do condicionamento físico com o passar do treinamento e a diminuição da liberação de CK [13].

Resultado similar foi encontrado por Maxwell e Colin [14], ao analisarem uma amostra de 15 homens treinados, os quais foram divididos em três grupos distintos. Dois grupos treinaram durante 30 dias em intensidade e duração diferentes, e o terceiro grupo não treinou nenhum dia. Ao final do treinamento, os três grupos realizaram uma corrida de $22,4 \mathrm{~km}$ onde foi constatada uma elevação significativa dos níveis de CK apenas no grupo que não treinou durante os 30 dias. Smith et al. [15], ao analisarem os efeitos do exercício prolongado em uma prova de maratona, encontraram correlação positiva entre o nível de condicionamento físico (mensurado através do tempo de realização da prova) e os níveis de $\mathrm{CK}$ avaliados após a maratona. Os dados apontaram menor liberação de CK nos atletas mais condicionados e maiores níveis de $\mathrm{CK}$ em atletas menos condicionados. Em estudo conduzido por Fallon et al. [16] foram encontrados resultados similares em uma prova de ultramaratona de $1600 \mathrm{~km}$. Koutedakis et al. [7] encontraram maior dano em remadores treinados do que em indivíduos saudáveis não remadores. Nesse caso todos os participantes foram testados em um protocolo exaustivo em esteira, e ao final do teste, os atletas remadores apresentaram maior elevação dos níveis de CK. Na prática do exercício físico, os atletas demonstram menor sensibilidade à liberação de $\mathrm{CK}$, apresentando menores quantidades da enzima quando comparados com indivíduos não treinados, possivelmente devido às adaptações relacionadas ao treinamento [18].

A literatura tem mostrado que a curva de CK não parece apresentar um comportamento padronizado, podendo sofrer variações antes, durante e após o exercício. A liberação de CK e sua taxa de depuração dependem do nível de treinamento, tipo, intensidade e duração do exercício. Pode-se observar elevação a partir de oito horas após a prática de um exercício vigoroso. Além disso, também se observa elevação entre o segundo e sétimo dia após exercícios excêntricos, associando a elevação à lesão muscular $[19,20]$. Outro estudo com ciclistas não treinados mostrou aumento significativo de CK após 90 minutos de exercício, sendo que o aumento continuou ocorrendo até o terceiro dia de exercício [21].

No presente estudo trabalhou-se com o percurso de $300 \mathrm{~km}$. Apesar da prova possuir essa característica, muitos ciclistas buscam o menor tempo possível e, pelo fato da maioria não possuir alto nível de condicionamento físico, sugere-se que estes possam apresentar um desgaste maior, e consequentemente maior dano muscular. Em geral, elevações maiores das concentrações de CK podem ser identificadas precocemente, permanecendo por maior intervalo de tempo. Geralmente os níveis de CK elevam-se em poucas horas após o exercício, atingindo um pico entre 24 horas e quatro dias, começando a diminuir a partir do terceiro dia $[19,20]$.

$\mathrm{O}$ fato de terem sido avaliados apenas 12 ciclistas pode ser visto como uma limitação deste estudo; mesmo assim, o resultado obtido foi significativo. Outros estudos que também avaliaram os níveis de $\mathrm{CK}$ em ciclistas obtiveram resultados similares. Um estudo recente com oito ciclistas competitivos avaliou diversos parâmetros bioquímicos, incluindo os níveis de CK; houve elevação nos níveis sérios de $C K$, contudo não foi encontrada diferença significativa após esforço máximo por 105 minutos no cicloergômetro [22]. Outro estudo avaliou as concentrações séricas de CK em 10 atletas de iromann, verificando um aumento significativo imediatamente após a prova e ainda quatro dias depois. Os autores sugerem que a elevação persistente pode estar associada ao desenvolvimento de lesões musculares durante esse tipo de competição de endurance, independente de serem atletas treinados ou indivíduos destreinados [23]. Ainda, Bessa et al. [24] avaliaram quatro ciclistas que pedalaram em alta intensidade por 25 minutos em forma de revezamento, até cada ciclista completar $200 \mathrm{~km}$. Ao final dos 800 $\mathrm{km}$ pedalados pelo grupo, foi encontrada elevação significativa de CK [24].

Um estudo avaliou um grupo de 31 homens com idade média de 19 anos que realizou caminhadas de 50 e $80 \mathrm{~km}$ ao nível do mar, em terreno sem pavimentação e carregando um peso sobressalente de $35 \mathrm{~kg}$. Em ambas as distâncias os valores de CK acompanharam a progressão, elevando-se paralelamente à distância percorrida [25]. França et al. [26] analisaram um grupo de 20 homens entre 25 e 40 anos de idade e dois anos de experiência em corridas de maratona. Os níveis de 
CK se mantiveram elevados por 20 horas após término da prova [26]. Esta elevação persistente da CK após o exercício pode servir para manter a demanda de ATP muscular durante a atividade, comprovando ser um indicativo da destruição da fibra muscular em resposta ao exercício extenuante. O exercício físico impõe ao organismo danos que devem ser compensados por mecanismos fisiológicos de adaptação além da adequação do treinamento e do estado nutricional.
Em suma, a sobrecarga imposta ao sistema esquelético durante diferentes tipos de exercício gera dano e dor muscular e, portanto, a avaliação dos níveis da CK pode contribuir para se avaliar o impacto do exercício físico em indivíduos não treinados, servindo como um marcador de fadiga ou sobrecarga. Os resultados deste estudo demonstram elevação nos níveis de creatina quinase após uma prova de ciclismo não competitivo de $300 \mathrm{~km}$, sugerindo a presença de dano muscular nessa modalidade de ciclismo.

\section{REFERÊNCIAS}

1. Brancaccio P, Lippi G, Maffulli N. Biochemical markers of muscular damage. Clin Chem Lab Med. 2010;48:757-67. http://dx.doi. org/10.1515/CCLM.2010.179

2. Takagi Y, Yasuhara T, Gomi K. Creatine kinase and its isozymes. Jap J Clin Pathol. 2001;Suppl 116:52-61.

3. Lang H, Wurzburg U. Creatine kinase, an enzyme of many forms. Clin Chem. 1982;28:1439-47.

4. Warren GL, Ingalls CP, Lowe DA, Armstrong RB. Excitation contraction uncoupling: major role in contractions induced muscle injury. Exerc Sport Sci Rev. 2001;29:82-7. http://dx.doi.org/10.1097/00003677-200104000-00008

5. Panteghini M, Bais R. Enzimas. In: Burtis, Carl A. et al. Tietz, eds. Fundamentos de Química Clínica. 6ª ed. Rio de Janeiro: Elsevier; 2008. p. 327-46.

6. Brancaccio P, Maffulli N, Limongelli FM. Creatine kinase monitoring in sport medicine. Brit Med Bull. 2007;81-82:209-30. http://dx.doi, org/10.1093/bmb/ldm014

7. Garry JP, McShane JM. Postcompetition elevation of muscle enzyme levels in professional football players. Med Gen Med. $2000 ; 3: \mathrm{E} 4$.

8. Mastaloudis A, Leonard SW, Traber MG. Oxidative stress in athletes during extreme endurance exercise. Free Radic Biol Med. 2001;31(7):911-22. http://dx.doi.org/10.1016/S0891-5849(01)00667-0

9. Hartmann U, Mester J. Training and overtraining markers in selected sport events. Med Sci Sports Exerc. 2000:32(1):209-15. http://dx.doi. org/10.1097/00005768-200001000-00031

10. Audax Club Parisien. Audax Club Parisien Randonneur- History. [Internet]. França; 2009. [Cited 2015 january 06]. Avaliable from: http:// www.audax-club-parisien.com/EN/21\%20-\%20Historic.html

11. World Health Organization. WHO Consultation on Obesity. Obesity: preventing and managing the global epidemic. Geneva;1998.

12. Pitanga FJG. Testes e avaliação em educação física. 3ª ed. São Paulo: Phorte; 2004.

13. Rumley AG, Pettigrew AR, Colgan ME, Taylor R, Grant S, Manzie A, Findlay I, Dargie H, Elliott A. Serum lactate dehydrogenase and creatine kinase during marathon training. Brit J Sports Med.1985;19:152-5. http://dx.doi.org/10.1136/bjsm.19.3.152

14. Maxwell JH, Bloor CM. Effects of conditioning on exertional rhabdomyolysis and serum creatine kinase after severe exercise. Enzyme. 1981;26:177-81.

15. Smith JE, Garbutt G, Pedoe DT. Effects of prolonged strenuos exercise (marathon running) on beochemical and hamatological markers used in the investigation of patients in the emergency department. Brit J Sports Med. 2004;38: 292-4. http://dx.doi.org/10.1136/bjsm.2002.002873

16. Fallon KE, Sivyer G, Sivyer K, Dare A. The biochemistry of runners in a 1600 km ultramarathon. Brit J Sports Med.1999;33:264-9. http:// dx.doi.org/10.1136/bjsm.33.4.264

17. Koutedakis Y, Raafat A, Sharp NC, Rosmarin MN, Beard MJ, Robbins SW. Serum enzyme activities in individuals with different levels of physical fitness. J Sports Med Phys Fit.1993;33:252-7.

18. Vincent HK, Vincent KR. The effect of training status on the serum creatine kinase response, soreness and muscle function following resistance exercise. Int J Sports Med. 1997;18:431-7. http://dx.doi.org/10.1055/s-2007-972660

19. Katirji B, Al-Jaberi MM. Creatine Kinase Revisited. J Clin Neuromuscul Dis. 2001;2:158-63. http://dx.doi.org/10.1097/00131402200103000-00008

20. Ross LF, Ramos LAM, Ramos RR, Araújo ARC. Rabdomiólise induzida por esforço físico intenso com altos níveis de creatinoquinase. Rev AMRIGS. 2009;53(3):269-72.

21. Totsuka M, Nakaji S, Suzuki K, Sugawara K, Sato K. Break point of serum creatine kinase release after endurance exercise. J Appl Physiol. 2002;93:1280-6.

22. Zajac A, Poprzecki S, Maszczyk A, Czuba M, Michalczyk M, Zydek G. The Effects of a Ketogenic Diet on Exercise Metabolism and Physical Performance in Off-Road Cyclists. Nutrients. 2014;6:2493-508. http://dx.doi.org/10.3390/nu6072493 
23. Machado CN, Gevaerd MS, Goldfeder RT, Carvalho T. Efeito do exercício nas concentrações séricas de creatina cinase em triatletas de ultradistância. Rev Bras Med Esporte. 2010;16(5):378-81. http://dx.doi.org/10.1590/S1517-86922010000500012

24. Bessa A, Nissenbaum M, Monteiro A, Gandra PG, Nunes LS, Bassini-Cameron1 A, Werneck-de-Castro JPS, Vaz de Macedo D, Cameron LC. High-intensity ultraendurance promotes early release of muscle injury markers. Brit J Sports Med. 2008;42:589-93. http://dx.doi. org/10.1136/bjsm.2007.043786

25. Chevion S, Moran DS, Heled Y, Shani Y, Regev G, Abbou B, Berenshtein E, Stadtman ER, Epstein Y. Plasma antioxidant status and cell injury after severe physical exercise. Proc Nat Acad Sci USA. 2003;100:5119-23. http://dx.doi.org/10.1073/pnas.0831097100

26. França SCA, Barros Neto TL, Agresta MC, Lotufo RFM, Kater CE. Resposta divergente da testosterona e do cortisol séricos em atletas masculinos após uma corrida de maratona. Arq Bras Endocrinol Metabol. 2006;50:1082-7. http://dx.doi.org/10.1590/S000427302006000600015 